De Felice, Petrillo/Measuring the attractiveness of socially responsible asset investments To Be Submitted to the International Symposium of the Analytic Hierarchy Process 2014, Washington D.C., U.S.A.

\title{
MEASURING THE ATTRACTIVENESS OF SOCIALLY RESPONSIBLE ASSENT INVESTMENTS
}

\author{
Fabio De Felice \\ University of Cassino and Southern Lazio \\ Cassino, FR, ITALY \\ E-mail: defelice@unicas.it \\ Antonella Petrillo \\ University of Naples "Parthenope" \\ Naples, NA, ITALY \\ E-mail: antonella.petrillo@uniparthenope.it
}

\begin{abstract}
Socially responsible investment is attracting more and more attention both in practice and in academia. A growing number of fund managers do invest while taking account of the societal effects of the companies they are investing in. In this study we present a AHP model to make investment decisions in which both financial return and social return dimensions are considered. We propose a model that can be used to define a measure of the ethical performance of the mutual funds that follow a Socially Responsible Investing (SRI) approach.

The final aim is to propose an index called "SRI index" that summarizes the "social, environmental and ethical performance" of each SRI-funds analyzed.
\end{abstract}

Keywords: Socially Responsible Investment, AHP, CSR 
De Felice, Petrillo/Measuring the attractiveness of socially responsible asset investments To Be Submitted to the International Symposium of the Analytic Hierarchy Process 2014, Washington D.C., U.S.A.

\section{Introduction}

Ever since the concept of investment for capital return was conceived, investors have based their investment choices on a variety of criteria, including whether investments harm or benefit society.

The European SRI Study 2012 shows that all responsible investment strategies surveyed have outgrown the market, and four out of six have grown by more than $35 \%$ per annum since 2009. The combined growth of all strategies at European level continues to outpace the overall investment market, demonstrating the continuous appetite by investors to take into account Environmental, Social and Governance factors, despite (or maybe due to) the ongoing economic and market turmoil. The origins of responsible investment are found in religious organisations. (Eurosif, 2012).

In the 2000s, investors combine the socially responsible aspect of investments with the concept of sustainable development, expanding the notion of SRI from Socially Responsible Investment to Sustainable and Responsible Investment. Today, SRI is an established industry, offering a variety of specialised and standardised products to both retail and institutional investors.

In Table 1 is shown European data.

Table 1: European Data Table

\begin{tabular}{|c|c|c|c|c|c|c|c|c|c|}
\hline $2011 € M n$ & $\begin{array}{l}\text { 1: Sustain- } \\
\text { ability themed } \\
\text { assets }\end{array}$ & $\begin{array}{l}\text { 2: Best-in-Class } \\
\text { and other Post- } \\
\text { tive Screens }\end{array}$ & $1+2^{*}$ & $\begin{array}{l}\text { 3: Norms-based } \\
\text { screening }\end{array}$ & $1+2+3^{*}$ & 4: Exclusions & 5: Integration & $\begin{array}{l}\text { 6: Engagement } \\
\text { and Voting }\end{array}$ & $1+2+3+4+5+6 *$ \\
\hline Austria & $€ 56$ & $€ 3,009$ & $€ 3,011$ & $€ 3,862$ & $€ 3,877$ & $€ 8,195$ & $€ 108$ & $€ 1,191$ & $€ 8,251$ \\
\hline Belglum & $€ 367$ & $€ 7,834$ & $€ 8,201$ & $€ 19,744$ & $€ 19,893$ & $€ 96,736$ & $€ 13,830$ & $€ 19,586$ & $€ 96,905$ \\
\hline Denmark & $€ 43$ & $€ 127$ & $€ 157$ & $€ 213,906$ & $€ 213,906$ & $€ 244,227$ & $€ 40,027$ & $€ 187,718$ & $€ 244,227$ \\
\hline Finland & $€ 322$ & $€ 24,798$ & $€ 25,120$ & $€ 62,336$ & $€ 87,157$ & $€ 83,637$ & $€ 20,715$ & $€ 44,870$ & $€ 107,600$ \\
\hline France & $€ 623$ & $€ 115,309$ & $€ 115,932$ & $€ 679,566$ & $€ 730,229$ & $€ 15,975$ & $€ 1,804,781$ & $\mathrm{~nm}$ & $€ 1,884,000$ \\
\hline Germany & $€ 4,523$ & $€ 13,115$ & $€ 17,477$ & $€ 11,255$ & $€ 19,988$ & $€ 618,248$ & $€ 11,424$ & $€ 7,927$ & $€ 621,020$ \\
\hline Italy & $€ 1,051$ & $€ 3,422$ & $€ 3,603$ & $€ 314,248$ & $€ 315,492$ & $€ 446,790$ & $€ 446$ & $€ 18,531$ & $€ 447,592$ \\
\hline Netherlands & $€ 19,914$ & $€ 1,120$ & $€ 20,602$ & $€ 166,359$ & $€ 168,425$ & $€ 665,108$ & $€ 542,156$ & $€ 472,019$ & $€ 666,248$ \\
\hline Norway & $€ 676$ & $€ 1,117$ & $€ 1,793$ & $€ 550,843$ & $€ 550,879$ & $€ 550,843$ & $€ 23,206$ & $€ 55,652$ & $€ 574,100$ \\
\hline Poland & $€ 0$ & $€ 13$ & $€ 13$ & $€ 13$ & $€ 13$ & $€ 1,174$ & $€ 13$ & $€ 0$ & $€ 1,174$ \\
\hline Spaln & $€ 107$ & $€ 1,558$ & $€ 1,665$ & $€ 1,119$ & $€ 2,022$ & $€ 56,226$ & $€ 7,302$ & $€ 11,094$ & $€ 57,091$ \\
\hline Sweden & $€ 396$ & $€ 86,134$ & $€ 86,530$ & $€ 259,346$ & $€ 343,002$ & $€ 339,754$ & $€ 34,897$ & $€ 137,660$ & $€ 378,300$ \\
\hline Swltzerland & $€ 11,079$ & $€ 23,093$ & $€ 29,565$ & $€ 192$ & $€ 29,757$ & $€ 429,194$ & $€ 7,509$ & $€ 4,946$ & $€ 441,637$ \\
\hline UK & $€ 8,932$ & $€ 2,559$ & $€ 9,154$ & $€ 63,520$ & $€ 69,959$ & $€ 273,180$ & $€ 697,692$ & $€ 989,211$ & $€ 1,235,201$ \\
\hline Europe & $€ 48,090$ & $€ 283,206$ & $€ 322,823$ & $€ 2,346,308$ & $€ 2554,597$ & $€ 3,829,287$ & $€ 3,204,107$ & $€ 1,950,406$ & $€ 6,763,347$ \\
\hline
\end{tabular}

To fully understand the key features of the Italian asset management industry, it is important to look at the savings trend and related financial investments of Italian households.

Institutional investors, essentially represented by pension funds, also play a major role in the development of the Italian market: since 2010, pension funds increasingly included SRI in their investment strategies and mandates, mainly through the adoption of SRI benchmarks within an 'active' management approach. Some progress was also made in terms of Engagement.

The future growth of the Italian SRI market depends on the positive signals coming from pension funds and insurance companies.

In Figure 1 is shown the Italian SRI Market Asset Allocation. 
De Felice, Petrillo/Measuring the attractiveness of socially responsible asset investments To Be Submitted to the International Symposium of the Analytic Hierarchy Process 2014, Washington D.C., U.S.A.

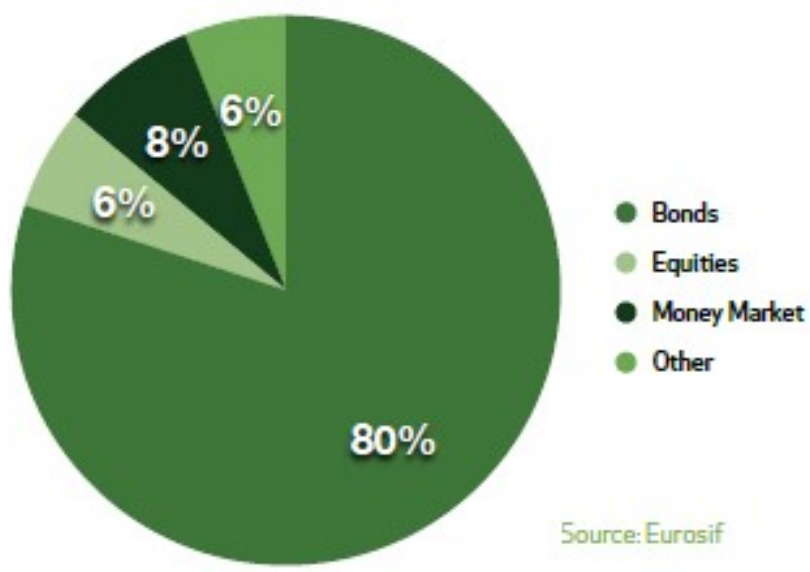

Figure 1: Italian SRI Market Asset Allocation

\section{Literature Review}

Over the past decade, socially responsible investments (SRI), frequently also called ethical investments or sustainable investments, have grown rapidly around the world. Socially Responsible Investing (SRI) is broadly defined as an investment process that integrates not only financial but also social, environmental, and ethical (SEE) considerations into investment decision making (Cabello et al., 2014).

Early research suggests that SRI funds either exhibit no performance difference from conventional funds (Shank et al., 2005). Really several SRI topics have been extensively investigated, with most of the existing empirical studies focusing on the financial performance of SRI funds, the theoretical background of SRI and flow-performance relation for SRI funds (Fernández and Matallin, 2008; Bollen, 2007; Galema et al., 2008) In this work we will rely on Vigeo's list of social, environmental, governance and ethical criteria as a departure point for the discussion and obtaining of an agreed list of nonfinancial criteria for socially responsible ranking of mutual funds.

\section{Hypotheses/Objectives}

The study has been developed for Italian funds and it has been born from a collaboration with Universitat Politècnica de València and Universidad de Oviedo.

\section{Research Design/Methodology}

We propose a model that incorporate:

- Ranking Mutual Funds according to Financial Criteria - Financial return

- Ranking Mutual Funds According to Socially Responsible Criteria - Social return

In details we propose the following step procedure to calculate the SRI index for each fund:

- Step 1. Select a set of attributes by which funds are evaluated.

- Step 2. Determine the weight of each attribute according to investors' tastes or preferences about the importance of the attribute to the portfolio attractiveness. 
De Felice, Petrillo/Measuring the attractiveness of socially responsible asset investments To Be Submitted to the International Symposium of the Analytic Hierarchy Process 2014, Washington D.C., U.S.A.

- Step 3. Evaluate the fund on each selected attribute.

- Step 4. Determine the total weighted score for each mutual fund.

In Figure 2 the AHP proposed model is presented. The criteria are:

- CORPORATE GOVERNANCE (CG): Effectiveness and integrity, guarantee of independence and efficiency of the Board of Directors, in particular the inclusion of social responsibility risks.

- BUSINESS BEHAVIOUR (BB): Consideration of the rights and interests of clients, integration of social and environmental standards in the selection of suppliers.

- ENVIRONMENT (ENV): Protection, safeguarding, prevention of damage to the environment, implementation of an adequate management strategy.

- HUMAN RESOURCES (HR): Continuous improvement of professional relations, labour relations and working conditions.

- HUMAN RIGHTS AT THE WORKPLACE (HRts): Respect of freedom of association, the right to collective bargaining, non-discrimination and promotion of equally.

- COMMUNITY INVOLVEMENT (CIN): Effectiveness, managerial commitment to community involvement, contribution to the economic and social development of territories/societies within which the company operates.

Figure 2: AHP model 
De Felice, Petrillo/Measuring the attractiveness of socially responsible asset investments To Be Submitted to the International Symposium of the Analytic Hierarchy Process 2014, Washington D.C., U.S.A.

\section{Data/Model Analysis}

This paper will present the results of an ongoing research that is not yet complete.

\section{Limitations}

The main limitation is the number of stakeholders involved in the project. The aim is to involve much more stakeholders.

\section{Conclusions}

In theory as well as in practice there is increasing interest in the issues of sustainability and social responsibility. This paper proposes a multi-objective approach for selecting portfolios with SRI-funds. The approach is based on the design of an index that measures the SRI performance of financial products. Main features of the model are: (1) a multidimensional description of the investment opportunities; (2) the measurement of attributes on the funds, and (3) a flexible procedure supporting the decision-maker in evaluating the tradeoffs between the selected fund and choosing a final fund that satisfies sustainable goals and constraints.

\section{Key References}

Bollen, N. P. B. (2007). Mutual fund attributes and investor behaviour. Journal of Financial and Quantitative Analysis, 42, 689-708.

Cabello, J.M., Ruiz, F., Pérez-Gladish, B., Méndez-Rodríguez, P. (2014). Synthetic indicators of mutual funds' environmental responsibility: An application of the Reference Point Method. European Journal of Operational Research 236 (2014) 313-325

European SRI Study (2012). Eurosif A.I.S.B.L., Belgium.

Fernández, M. A., \& Matallin, J. C. (2008). Performance of ethical mutual funds in Spain: Sacrifice or Premium? Journal of Business Ethics, 81(2), 247-260.

Galema, R., Plantinga, A., \& Scholtens, B. (2008). The stocks at stake: Return and risk in socially responsable investment. Journal of Banking and Finance, 32, 2646-2654.

Shank, T., Manullang, D., Hill, R., (2005). Doing well while doing good revisited: a study of socially responsible firms' short-term versus long-term performance. Managerial Finance 31 (8), 33-46. 